\title{
Corporate Environmental Reporting and News Coverage of Environmental Issues: An Agenda-Setting Perspective
}

Pre-print version of:

Pollach, I. (2014). Corporate Environmental Reporting and News Coverage of Environmental Issues: An Agenda-Setting Perspective, Business Strategy and the Environment, 23(5), 349-360.

\section{Introduction}

Mounting environmental problems have led to increasing communication about environmental issues and solutions in both the news media and corporate discourse. Corporations communicate about their efforts to reduce their environmental footprint in order to gain or maintain their social legitimacy. They publish environmental reports for their internal and external stakeholders, providing an account of their achievements and outlining their future goals regarding environmental sustainability. This study focuses on the connection between the content of corporate environmental reporting and the news coverage of environmental issues. Departing from agenda setting theory (McCombs \& Shaw, 1972), this paper explores whether content in news coverage and the corporate environmental agendas presented in corporate reports are connected. The remainder of the paper is organized as follows: First the relevant literature on environmental reporting is reviewed, before agenda setting theory is introduced as the theoretical framework. Next, the methodology behind the data collection and analysis is described. Ultimately, the results are presented and discussed.

\section{Social and Environmental Reporting}

Corporate social responsibility (CSR) reports are variously called sustainability reports, social reports, or environmental reports, depending on their content. Although this paper focuses on environmental reporting only, the literature on both environmental reporting and CSR reporting has been reviewed, since the findings on CSR reporting are also relevant to environmental reporting. CSR reports document how companies address their social and/or environmental responsibilities in the marketplace, the workplace, the supply chain, and the community. Such reports resemble the format and structure of annual financial reports in that they provide measures of a company's performance 
and may even be verified by a third-party auditor (Brown \& Deegan, 1998). Over the past few decades, social and environmental reporting has become a de-facto standard for very large corporations of all industries (KPMG, 2002). It is particularly high-impact industries, such as resource-based industries, manufacturers, or producers of chemicals, that have been subject to growing pressures from governments, supranational bodies, and environmental interest groups to address environmental problems and disclose environmental information (Deegan \& Gordon, 1996; Hunter \& Bansal, 2007; Haddock-Fraser \& Fraser, 2008; Mio, 2010). For these reasons it is not surprising that previous research has found disclosure levels in high-impact industries to be higher than in other industries (Clarke \& Gibson-Sweet, 1999; Cormier \& Magnan, 2004; Deegan \& Rankin, 1996; Esrock \& Leichty, 1998; Gray et al., 2001; Jose \& Lee, 2007; Kolk et al., 2001). This may have to do with the general documentation requirements these companies are subject to, which enable them to publish environmental reports at little extra cost, unlike companies from low-impact or medium-impact industries. Even industries whose direct environmental impact is low, such as banking and financial services, have jumped on the bandwagon of environmental reporting (cf. Kolk et al., 2001; Cormier \& Magnan, 2004; Jose \& Lee, 2007; Carnevale et al., 2012). Although their direct environmental impact is low, their lending activities to high-impact industries can haven a substantial indirect impact on the environment (Thompson \& Cowton, 2004; Kolk et al., 2001; O'Sullivan \& O'Dwyer, 2009). Because of such indirect effects, low-impact industries have come under the same pressures to disclose environmental information as high-impact industries (Ramus \& Montiel, 2005, Scholtens, 2009).

Multiple reasons why corporations adopt environmental policies and communicate them to external stakeholders have been identified on the basis of theoretical and empirical inquiries. For high-impact industries such reasons include, first and foremost, compliance with reporting legislation they are subject to in many countries (Azzone et al., 1996; Banerjee, 2002) or efforts to preempt adverse future regulation (Brammer \& Pavelin, 2006). Other expected outcomes of environmental reporting include economic advantages in the form of enhanced corporate reputations (Clarke \& Gibson-Sweet, 1999) and a lower risk of stockholder resolutions (Dawkins \& Fraas, 2011). In addition, disclosing environmental information voluntarily in the form of environmental reports reduces the efforts external stakeholders have to undertake in order to gather such information, if they are interested in a company's environmental affairs. At the same time, publishing such reports entails the risk that these external stakeholders will challenge the company on the way it runs its business, which then may require operational changes (Dawkins \& Fraas, 2011).

Banerjee et al. (2003) identified public concern and regulatory forces as the main drivers of environmental reporting in high-impact sectors, while competitive advantage had the greatest impact among companies in moderate-impact industries. For low-impact companies, it has been argued that their environmental communication is either a manifestation of corporate values and commitments or a mimicking response to competitive pressures in the industry (Baker \& Sinkula, 2005). Companies typically mimic more successful companies in order to maintain their legitimacy, thereby initiating an industry-wide adaptation process that results in the institutionalization of particular practices (cf. DiMaggio and Powell 1983; Zucker 1987). This institutionalization process has also started with regards to CSR reporting (Matten \& Moon, 2008). Also, brand-name companies and 'close-to-market' companies have been found to be more likely to publish environmental reports than other companies (Haddock-Fraser \& Fraser, 2008). In a qualitative study, Spence (2009) found that employees - after investors - are the second most important target audience of social and environmental reports. Thus, 
environmental reports are also published to satisfy information needs within the company. Overall, it can be concluded that companies disclose environmental reports because of legislation or the threat thereof, competition, mimicry, visibility and stakeholder information demands.

\section{Agenda Setting Theory}

Agenda setting theory goes back to McCombs and Shaw (1972) and their study of how political news coverage of presidential campaigns determines public opinion. They concluded that the news media have a strong influence on what people considered major issues in a presidential campaign. The core assertion of agenda setting theory is that salient issues are transferred from the media agenda to the public agenda, and agenda setting is to be seen as the news media's creation of public awareness of an issue. Thus, the more the news media report about particular issues, the more prominence these issues will gain among the general public (McCombs et al., 1997). The power of the news media in setting the agenda for the public discourse manifests itself at two levels: The first level of agenda setting is the awareness of the importance of an issue that is created by the media when they cover an issue, while the second level refers to attributes that are ascribed to an issue based on how the media comment on this issue.

Zucker (1978) argued that the news media have a greater agenda-setting effect when they cover unobtrusive issues, i.e. issues for which individuals have next to no other source of information and little direct contact, than for obtrusive issues, for which there are other sources of information, so that people do not have to rely solely on news media for information. According to Zucker, the environment and its pollution are such an unobtrusive issue. Ader (1993) confirmed this in her study of the news coverage of pollution and the salience of environmental issues on the public agenda. She found a positive correlation between news coverage and issue saliency. She also argued that citizens have no means to check a particular company's environmental impact, but may be considerably affected by it, which is why the news media play a crucial role in shaping people's environmental concerns and attitudes (Ader, 1993). More recently, climate change has been identified as an issue where the general public has to rely on the news media as intermediaries between citizens, scientists and politicians (Olausson, 2011).

Previous research has also provided evidence that-in the case of the environment-the public sets the media agenda to some extent. It has been argued that the media have agenda-setting effects on the general public mainly when reporting about newsworthy events such as wars, crimes or government scandals, which audiences would be naturally interested in. For issues that do not necessarily constitute such spectacular events, including for example environmental problems, news coverage is driven by the public's concerns about the issue, including policy makers. Thus, public concerns about environmental problems rather than pure newsworthiness drive the media agenda in this case (Uscinski, 2009; Trumbo, 1995).

Since its inception, agenda setting theory has been applied with robust results mainly to political communication (e.g. Cohen, 1995; Holbrook \& Hill, 2005; Kiousis et al., 2005). To a lesser extent, agenda setting has also been applied to the relationship between news media and corporations. The news media are important agenda-setters in the business world. By reporting positively about 
management concepts and ideas, they give legitimacy to corporate activities (Hellgren et al., 2002). Organizations are more likely to address particular social issues after these have been addressed in the news media (Deephouse \& Heugens, 2009). In a study on CSR in the business press, Grafström and Windell (2011) found that the news media integrate the voices of NGOs, politicians, consultants, and corporations into their coverage of CSR. They argue that the news media construct and frame CSR and the notion of responsible companies by choosing and linking these voices in particular ways. Thus, the media do not set the media agenda without any outside influences, but also give selected actors the space to voice their viewpoints.

Corporations also play active roles within the agenda-setting framework. First, they are objects that are talked about in the news media, which brings these companies to the awareness of the general public, who then forms opinions about individual companies and their activities (Carroll \& McCombs, 2003; Kiousis et al., 2007; Meijer \& Kleinnijenhuis, 2006). Second, corporations are agenda-setting advocates, for example when they try to influence the news media agenda to their advantage or when lobbyists seek to translate corporate agendas into federal policy issues (Berger, 2001).

\section{Research question}

Previous research on corporate environmental communication has typically studied the content (e.g. Jose \& Lee, 2007; Chen \& Bouvain, 2009; Pollach et al., 2009; Hou \& Reber, 2011) or rhetoric (e.g. Ihlen, 2009; Smerecnik \& Renegar, 2010; Castelló \& Lozano, 2011) of corporate environmental communication. There is also a stream of research that has studied CSR content in newspapers. For example, one study on the news coverage of CSR has found that CSR news tends to be positive rather than negative (Zhang \& Swanson, 2006). A longitudinal study of newspaper coverage of CSR has shown an increasing number of opinion pieces on CSR in newspapers over a 25 -year period (Lee \& Carroll, 2011). The only study that has previously investigated the link between news coverage and corporate environmental reporting from an agenda-setting perspective is over a decade old and was limited to a small sample of Australian high-impact companies. The authors found that corporate reporting content is associated with news coverage of environmental issues. However, they did not factor in time lags and therefore were not able to draw conclusions about who influences whom (Brown \& Deegan, 1998), even though agenda setting theory posits that there is a time lag between the media coverage of an issue and the public agenda (McCombs, 1977).

This study compares the environmental agendas of news media and corporate environmental agendas with time lags of up to +/- 2 years to explore how closely they are related. Thus, the paper explores whether the news media set corporate agendas or companies set the public and hence the media agenda. In view of the little research that has been conducted on the interplay between environmental agendas set by corporations and environmental agendas set by the news media, this study makes a contribution to both the literature on agenda setting and the literature on corporate environmental communication. 


\section{Methodology}

Corporate reports and newspaper content published over a period of 12 years were compared against a list of environmental terms. The following sections describe how the corporate reports were collected, how the newspapers were selected, and how the list of environmental terms was compiled.

\section{Corporate Environmental and Annual Reports}

Since environmental reporting has been found to be positively associated with company size (Brammer \& Pavelin, 2008; Deegan \& Rankin, 1996; Fortanier \& Kolk, 2007; Jenkins \& Yakovleva, 2006; Meek et al., 1995; Niskala \& Pretes, 1995), the sample was chosen from the largest companies in the world. The Forbes 2000 ranking from the year 2008 was used to identify these companies. To enable comparisons of companies from different parts of the world, companies from North America and Western Europe were included in the sample. Asia Pacific, South America, and Eastern Europe were not included, because there were not enough large companies from these regions among the Forbes 2000.

Environmental reporting has been studied in a number of industries, which have often been split into high-impact industries (e.g. Bowen, 2000; Jose \& Lee, 2007; Lober et al., 1997), medium-impact industries (Banerjee et al., 2003), and low-impact industries (e.g. Banerjee et al., 2003; Jose \& Lee, 2007; Kolk et al., 2001; Stray \& Ballantine, 2000). High-impact companies include companies from industries that have a big environmental footprint, including utilities, chemicals, oil, pulp and paper (Bowen, 2000; Jose \& Lee, 2007; Lober et al., 1997). This study does not include high-impact industries, since the role of legislation and regulation can be expected to have a significant impact on the environmental policies of these companies. For example, since the early 1990s, the US Environmental Protection Agency's Toxics Release Inventory has required companies from polluting industries to report on waste, water discharge, and air emissions containing toxic substances. The industries subject to this requirement include chemical and industrial manufacturers, electronics manufacturers, mining, petroleum, and utilities companies (US Environmental Protection Agency, 2012) and correspond to the high-impact companies mentioned above. This reporting requirement may influence the content of their environmental reporting and would distort a potential association with news media coverage. Therefore, this study does not consider the high-impact sector. Only lowimpact companies and medium-impact companies were selected for this study.

Previous studies on corporate environmental reporting have identified banking, financial services, and insurance (Stray \& Ballantine, 2000; Kolk et al., 2001; Jose \& Lee, 2007) as industries whose direct impact on the environment is relatively low. Nevertheless, environmental reporting is still important for these companies, even if the direct impact of their operations is low, given that their indirect impact through lending, for example, may be quite substantial (Kolk et al., 2001). Therefore, these industries were included and are henceforth referred to as 'financial services' companies. Further, Banerjee et al. (2003) have identified services, consumer products and foods as medium-impact companies. Of these, consumer products and foods were included in the study. These industries are represented in the Forbes ranking as Food, Drink \& Tobacco, Food Markets, Retailing, and Household \& Personal Products. These companies are henceforth referred to as 'consumer goods' companies.

Overall, 223 companies in Europe and North America were found for these industries in the Forbes ranking. Since companies report environmental information in stand-alone reports or in their 
annual reports, each company's website was accessed and all annual reports and environmental/CSR reports that were made available in English were downloaded. Annual reports were not downloaded for those years in which the company published an environmental/CSR report. Sixteen companies did not make any reports available, had gone bankrupt or had been acquired by another company since the publication of the Forbes ranking. The study was therefore conducted with reports from 207 companies. The earliest report dated back to 1992. Since only few reports were found from the early and mid-1990s, the years 1992 to 1996 were excluded from the study, because these small samples would have made it difficult to obtain significant findings. The study thus covers the period from 1997 to 2008 , which has resulted in a total of 1,668 reports that were examined.

Table 1 displays the total number of annual and CSR reports found for each period. Since the period from 1992 to 1996 was excluded from the study, the horizontal sum total covers only the period from 1997 to 2008. The reports downloaded were all in pdf format and had to be converted into txt files to permit processing with textual analysis software. The software tool WordStat was used to process the reports and count the frequencies of the environmental terms for each year.

\section{Insert Table 1}

\section{Newspapers}

The newspapers included in the study were chosen from the Factiva database. All European and US English-language newspapers available from Factiva were included to measure the amount of attention certain environmental terms have received in the news media. The number of newspaper articles that mention these terms per year was obtained from the Factiva database for the period from 1995 to 2009. Duplicates were excluded.

\section{Environmental Terms}

The goal was to compile a list of environmental terms, whose occurrence is then studied in the news media as well as in corporate environmental reports. The following three sources were used to compile this list: First, a glossary of over 100 environmental terms published by the US Environmental Protection Agency (2011) was used. Second, a list of 56 environmental problems published by the EU's European Environment Agency (1995) was used. Third, 42 sustainable development issues identified by the United Nations (2009) as part of its Agenda 21 program were included in the list. These sources were selected in order to obtain lists of rather general environmental terms that were compiled by both government agencies from different regions as well as supranational organizations and stem from different years, which is important for a longitudinal study. 
Not all terms on these lists turned out to be useful for the study, since they also contained terms that were more relevant to municipalities and citizens than to companies (e.g. terms related to municipal waste or traffic management), terms that were strictly speaking not environmental issues (e.g. terms related to health, poverty), and terms that were not relevant to financial services or consumer goods (e.g. nuclear waste, coastal erosion). In addition, there were terms that were simply too specific for the present analysis, as they are unlikely to be salient media issues or corporate issues (e.g. noxious gases, cryptosporidium, tropospheric ozone). After these eliminations, 39 terms were left. They had to be adapted to reduce possible errors in the subsequent computer-assisted processing. Multi-word expressions were reduced to one or two headwords, e.g. loss of biodiversity was reduced to biodiversity, and alternative energy sources was shortened to alternative energy/energies.

After the word counts of the terms had been obtained, it turned out that a number of environmental terms occurred so infrequently in both corporate reports and newspapers that they were eliminated from the study. As a rule of thumb, a term was eliminated, if its total frequency over the entire period was lower than $1 / 7$ of the overall average frequency over that period in both the corporate reports and the newspaper articles. By applying this rule, 14 environmental terms were excluded and the study continued with 25 environmental terms. The list of environmental terms identified is found in Table 2. Those terms that were identified but eliminated due to low frequencies are listed separately.

\section{Insert Table 2}

\section{Results}

Correlations were calculated between the frequencies with which an environmental term occurred in the newspapers over the period studied and the frequencies with which the same term was used in the environmental and annual reports. Since the number of corporate reports varied from year to year, the average of those frequencies was used. The correlations were calculated for samples with a one-year time lag and a two-year lag in both directions, as well as without a lag. For example, the correlation between term frequencies in corporate reports from 2004 was correlated with the frequencies in newspaper content from 2002, 2003, 2004, 2005, and 2006. It was not possible to record at which point in the respective year an annual report or CSR report was written. Therefore, it was also not taken into account at which point in time exactly a newspaper article was published.

Correlations are clearly limited in that they do not indicate directionality. However, when comparing correlations over five different time lags (from -2 to +2 years), some indication of directionality can become visible. The correlation results can be found in Table 3 . All significant correlations are positive, indicating that the growth in news coverage of these terms mirrors the growth in corporate reporting of these issues. Groundwater is the only term for which no correlations were found, which can be explained by the fact that the average corporate reporting frequency 
oscillated over the time period, while news coverage rose steadily. The situation is similar for Kyoto protocol/agreement, for which both corporate reporting and news coverage oscillated.

Most relationships have the strongest association in a situation without a lag. The terms for which the association between media coverage and report content is particularly evident include biodegradable, global warming, pollution, and waste management. For these concepts, it is clear that media coverage and corporate reporting are not only significantly associated but also that this association is of an immediate nature, as next to no correlations were found for the situations with time lags.

\section{Insert Table 3}

Next to all terms have the strongest correlations in the span from -1 to +1 year lags. Those terms for which the strongest correlations were found outside the $+/-1$ year time frame are biodiversity, energy use, and solar energy. Energy use has its strongest correlations for the -2 year lag, but has strong correlations in the other situations as well. Solar energy, meanwhile, has strong correlations in the negative-to-zero lag situations, but not with positive time lags. The reason for this is that corporate reporting of this concept went down in the last two years, on average, while media coverage increased steadily. For this issue, the media have thus not set the corporate agenda for the sample companies, at least not in the last two years of the study. Although biodiversity has its strongest correlation for the +2 -year lag, the other correlations are very close to this one.

Even though correlations alone cannot give an indication of the directionality underlying the associations, the mere word frequencies can give an indication for those terms that did not have any frequencies in corporate reports in the early years of the period studied. These issues include alternative energy/energies, carbon emissions, carbon footprint, and environmental footprint. Their average frequencies in corporate reports as well as the frequencies in the newspapers are visualized in Figures 1 and 2. The figures have a logarithmic scale on the y-axis in order to account for the differences in frequencies between corporate reporting and news coverage. The figures clearly indicate that corporate reporting follows news coverage.

Insert Figure 1 


\section{Insert Figure 2}

Since the sample contains companies from both low-impact industries (financial services) and medium-impact industries (consumer goods), the two groups are examined qualitatively for differences regarding the coverage of the above environmental issues. In order to examine the average term frequencies for each industry in the period from 1997 to 2008, graphs for the average usage of each term in both industries were drawn and compared visually. Some terms were, on average, adopted much faster in the consumer-goods industry (e.g. biodiversity, biodegradable, groundwater, landfill) or in the financial industry (alternative energies, carbon emissions, global warming, wind power) than in the respective other industry. Figure 3 displays one example of each situation, indicating that energy use was used much more frequently in the consumer-goods industry, whereas alternative energies was adopted much faster in the financial industry. To some extent, these differences can be attributed to the varying relevance of particular issues to different industries (e.g. landfills in the consumer-goods industry), but at the same time, differences between the two industries were also found for environmental issues that are not industry-specific (e.g. global warming).

\section{Insert Figure 3}

A number of other environmental terms were adopted at the same pace in both industries (e.g. carbon footprint, CO2, environmental footprint, sustainability). The two terms global warming and fossil fuels showed and increase in one industry and a peak-out and decline in the other industry. Figure 4 displays one example of these two conditions, indicating that environmental footprint was adopted at the same pace in both groups and that the term fossil fuels grew and peaked out in the consumer-goods industry and started to grow much later in the financial industry. In addition, there were several environmental terms, which oscillated over the period studied, so that no pattern could be determined (e.g. Kyoto protocol, renewable energy, solar power). Overall, mixed results were obtained from the examination of industry differences and no general trend could be observed. 


\section{Insert Figure 4}

\section{Discussion}

This paper has explored agenda setting between corporations and the news media regarding environmental issues. The frequency of common environmental issues in news coverage and environmental reporting content was compared, and correlations between the two were calculated with time lags of up to +/- 2 years. Further, low-impact and medium-impact industries were compared.

The findings indicate that the news media clearly impact corporate environmental agendas for some of the issues studied, including carbon emissions, alternative energies, environmental footprint, and carbon footprint. This is in line with what the literature review suggests about organizations adopting practices covered in the news media in order to maintain their legitimacy (cf. Hellgren at al., 2002). The news media thus play a crucial role as propagators of legitimacy and, ultimately, corporate environmental discourse. Whether and how they report on environmental issues can thus influence the inclusion of environmental issues in corporate environmental disclosures.

Another finding is that the strongest correlations were found for the years without time lags for most of the environmental issues. Thus, there was no noticeable delay between corporate reports and news reports. This indicates that the corporate environmental agendas and the news agenda mirror each other. However, mirroring does not mean that they are independent of each other. Rather, companies or the news media pick up environmental issues from each other so fast that we cannot measure the effect in a study based on corporate reports published annually. Although the results could also mean that third parties influence these two agendas, the opposite has been suggested by previous research (cf. Grafström \& Windell, 2011), which found that the news media give space to voices from governments, NGOs, and other experts. Thus, it is then again the news media that decide whether these debates are transferred to the public agenda, and any agenda-setting effect would be an indirect one mediated by the news media.

The comparison between the financial industry (low impact) and the consumer-goods industry (medium impact) revealed that there are differences between the industries as to when and to what extent different industries pick up particular issues, but no general trends were found. The findings suggest that these differences can be attributed to both the relevance of the issue to a particular industry as well as individual companies' environmental strategies. In addition, there were environmental issues that were adopted at the same pace in both industries, which again suggests an influence of the news media as agenda setters and propagators of environmental issues.

The findings further suggest that companies need to be aware that the news media have the potential to create concerns among all corporate stakeholders when they select the stories to be published and when they choose how to report on events. It is critical for companies to scan the news 
coverage of environmental issues when making their environmental strategies in order to anticipate and proactively address environmental concerns before they become major public issues. Therefore, media monitoring of environmental news coverage needs to be an integral part of corporate environmental management.

This study is not without limitations. A limitation of the study is that the company data consisted only of reports. Companies may address environmental issues in a more comprehensive format on their corporate websites or in other internal documents. However, the reports can be seen as the backbone documents that summarize all corporate initiatives taken throughout one year. Another limitation lies in the news sources that were selected. The variable included is the number of articles that have been published on a particular issue, assuming that all articles receive equal consideration. Thus, the effects of photographs, headings, font sizes, and front-page articles cannot be considered here. Also, different media types have different agenda-setting potentials, but only print newspapers were considered in this study. TV news coverage, documentaries and films, for example, may impact on corporate environmental agendas, which this study could not take into account.

Since this study is the first large-scale investigation of its kind using an agenda-setting framework, the chosen methodology can provide inspiration for the design of future studies on environmental agenda setting. Future research could investigate particular environmental issues in more detail rather than covering a broad range of environmental terms. This study provides a list of environmental issues and problems that can be used for more detailed investigations of specific issues in the future. Future studies could also derive such a list inductively from the corporate reports and compare environmental issues that were high on the corporate agendas in particular years with news content. Another issue that warrants qualitative exploration is the early environmental reports that were excluded from this study. They can be seen as pioneer reports that may have been very influential for environmental reporting by other companies. Further, future research could also extend this study by focusing on reporting in those regions that were not covered in this study, e.g. Asia Pacific, South America, and Eastern Europe, and compare them with news coverage from these regions. Ultimately, the many significant correlations obtained for the situations without time lags suggest that time lags of $+/-1$ year will suffice in future studies. It does, however, not seem to be appropriate to conduct such a study completely without time lags, as the exact publication date of environmental reports is unknown.

\section{Conclusion}

Overall, the paper contributes insights into the relationship between news content and corporate reporting on environmental issues. In particular, it furnishes proof of the news media setting corporate agendas. News media have been found to play a crucial role, which means that agendasetting theory is appropriate in order to understand the role of news media in corporate environmental communication. 


\section{References}

Ader, C.R. (1993). A longitudinal study of agenda setting for the issue of environmental pollution. Journalism and Mass Communication Quarterly, 72(2), 300-311.

Azzone, G., Manzini, R. \& Noci, G. (1996). Evolutionary trends in environmental reporting. Business Strategy and the Environment, 5, 219-230.

Baker, W.E., \& Sinkula, J.M. (2005). Environmental marketing strategy and firm performance: Effects on new product performance and market share. Journal of the Academy of Marketing Science, 33(4), 461-475.

Banerjee, S.B. (2002). Corporate environmentalism. The construct and its measurement. Journal of Business Research, 55, 177-191.

Banerjee, S.B., Iyer, E.S., \& Kashyap, R.K. (2003). Corporate environmentalism: Antecedents and influence of industry type. Journal of Marketing, 67, 106-22.

Berger, B.K. (2001). Private issues and public policy: Locating the corporate agenda in agenda-setting theory. Journal of Public Relations Research, 13(2), 91-126.

Bowen, F.E. (2000). Environmental visibility: A trigger of green organizational response? Business Strategy and the Environment, 9, 92-107.

Brammer, S., \& Pavelin, S. (2008). Factors influencing the quality of corporate environmental disclosure. Business Strategy and the Environment, 17, 120-36.

Brammer, S., \& Pavelin, S. (2006). Voluntary environmental disclosures by large UK companies. Journal of Business Finance \& Accounting, 33(7/8), 1168-88.

Brown, N., \& Deegan, C. (1998). The public disclosure of environmental performance information-a dual test of media agenda setting theory and legitimacy theory. Accounting and Business Research, 29(1), 21-41.

Carnevale, C., Mazzuca, M., \& Venturini, S. (2012). Corporate social reporting in European banks: The effects on a firm's market value. Corporate Social Responsibility \& Environmental Management, 19(3), 159-177.

Carroll, C. E., \& McCombs, M.E. (2003). Agenda-setting effects of business news on the public's images and opinions about major corporations. Corporate Reputation Review, 6 (1), 36-46.

Castelló, I., \& Lozano, J. (2011). Searching for new forms of legitimacy through corporate responsibility rhetoric. Journal of Business Ethics, 100(1), 11-29.

Chen, S., \& Bouvain, P. (2009). Is corporate responsibility converging? A comparison of corporate responsibility reporting in the USA, UK, Australia, and Germany. Journal of Business Ethics, 87, 299-317.

Clarke, J., \& Gibson-Sweet, M. (1999). The use of corporate social disclosures in the management of reputation and legitimacy: A cross sectoral analysis of UK top 100 companies. Business Ethics: A European Review, 8(1), 5-13. 
Cohen, J. E. (1995). Presidential rhetoric and the public agenda. American Journal of Political Science, 39, 87-107.

Cormier, D., \& Magnan, M. (2004). The impact of the Web on information and communication models: The case of corporate environmental disclosure. International Journal of Technology Management, 27(4), 393-416.

Dawkins, C., \& Fraas, J.W. (2011). Coming clean: The impact of environmental performance and visibility on corporate climate change disclosure. Journal of Business Ethics, 100, 303-322.

Deegan, C., \& Gordon, B. (1996). A study of the environmental disclosure practices of Australian corporations. Accounting and Business Research, 26(3), 187-199.

Deegan, C., \& Rankin, M. (1996). Do Australian companies report environmental news objectively? An analysis of environmental disclosures by firms prosecuted successfully by the Environmental Protection Authority. Accounting, Auditing \& Accountability Journal, 9(2), 50 67.

Deephouse, D. L., \& Heugens, P. P. (2009). Linking social issues to organizational impact: The role of infomediaries and the infomediary process. Journal of Business Ethics, 86(4), 541-553.

DiMaggio, P.J., \& Powell, W.W. (1983). The iron cage revisited: The institutional isomorphism and collective rationality in organizational fields. American Sociological Review, 48(2), 147-160.

Esrock, S.L., \& Leichty, G.B. (1998). Social responsibility and corporate Web pages: Self-presentation or agenda-setting? Public Relations Review, 24(3), 305-319.

European Environment Agency (1995). Europe's environment. Appendix 1: Inventory of 56 environmental problems. Retrieved December 6, 2011, from http://www.eea.europa.eu/publications/92-826-5409-5/page042.html.

Fortanier, F., \& Kolk, A. (2007). On the economic dimensions of corporate social responsibility: Exploring Fortune Global 250 reports. Business \& Society, 46(4), 457-478.

Grafström, M., \& Windell, K. (2011). The role of infomediaries: CSR in the business press during 2000-2009. Journal of Business Ethics, 103, 221-237.

Gray, R.H., Javad, M., Power, D.M., \& Sinclair, C.D. (2001). Social and environmental disclosure and corporate characteristics: A research note and extension. Journal of Business Finance and Accounting, 28, 327-57.

Haddock-Fraser, J., \& Fraser, I. (2008). Assessing corporate environmental reporting motivations: Differences between 'close-to-market' and 'business-to-business' companies. Corporate Social Responsibility and Environmental Management, 15, 140-155.

Hellgren, B., Löwstedt, J., Puttonen, L., Tienari, J., Vaara, E., \& Werr, A. (2002). How issues become (re)constructed in the media: Discursive practices in the AstraZeneca merger. British Journal of Management, 13(2), 123-140.

Holbrook, R.A., \& Hill, T.G. (2005). Agenda-setting and priming in prime time television: Crime dramas as political cues. Political Communication, 22, 277-295. 
Hou, J., \& Reber, B.H. (2011). Dimensions of disclosures: Corporate social responsibility (CSR) reporting by media companies. Public Relations Review, 37(2), 166-168.

Hunter, T., \& Bansal, P. (2007). How standard is standardized MNC global environmental communication? Journal of Business Ethics, 71, 135-47.

Ihlen, Ø. (2009). Business and climate change: The climate response of the World's 30 largest corporations, Environmental Communication, 3(2), 244-262.

Jenkins, H., \& Yakovleva, N. (2006). Corporate social responsibility in the mining industry: Exploring trends in social and environmental disclosure. Journal of Cleaner Production, 14, 271-84.

Jose, A., \& Lee, S.M. (2007). Environmental reporting of global corporations: A content analysis based on website disclosures. Journal of Business Ethics, 72, 307-321.

Kiousis, S., Popescu, C., \& Mitrook, M. (2007). Understanding influence on corporate reputation: An examination of public relations efforts, media coverage, public opinion, and financial performance from an agenda-building and agenda-setting perspective. Journal of Public Relations Research, 19(2), 147-65.

Kiousis, S., McDevitt, M., \& Wu, X. (2005). The genesis of civic awareness: Agenda setting in political socialization. Journal of Communication, 55, 756-74.

Kolk, A., Walhain, S., \& van de Wateringen, S. (2001). Environmental reporting by the Fortune Global 250: Exploring the influence of nationality and sector. Business Strategy and the Environment, 10(1), 15-28.

KPMG (2002). KPMG international survey of environmental reporting 2002. DeMeern: KPMG Environmental Consulting.

Lee, S., \& Carroll, C. (2011). The emergence, variation, and evolution of corporate social responsibility in the public sphere, 1980-2004: The exposure of firms to public debate. Journal of Business Ethics 104(1), 115-131.

Lober, D.J., Bynum, D., Campbell, E., \& Jacques, M. (1997). The 100 plus corporate environmental report study: A survey of an evolving environmental management tool. Business Strategy and the Environment, 6, 57-73.

Matten, D., \& Moon, J. (2008). 'Implicit' and 'explicit' CSR: A conceptual framework for a comparative understanding of corporate social responsibility. Academy of Management Review, 33(2), 404424.

McCombs, M.E., \& Shaw, D.L. (1972). The agenda-setting function of mass media. Public Opinion Quarterly, 36(Summer), 176-87.

McCombs, M.E. (1977). Agenda setting function of mass media, Public Relations Review, 3(4), 89-95.

McCombs, M.E., Llamas, J.P., Lopez-Escobar, E., \& Rey, F. (1997). Candidate images in Spanish elections: Second level agenda setting effects. Journalism \& Mass Communication Quarterly, 4, 703-717. 
Meek, G.K., Roberts, C.B., \& Gray, S.J. (1995). Factors influencing voluntary annual report disclosure by US, UK and continental European multinational corporations. Journal of International Business Studies, 26(3), 555-572.

Meijer, M.-M., \& Kleinnijenhuis, J. (2006). Issue news and corporate reputation: Applying the theories of agenda setting and issue ownership in the field of business communication. Journal of Communication, 56, 543-59.

Mio, C. (2010). Corporate social reporting in Italian multi-utility companies: An empirical analysis. Corporate Social Responsibility and Environmental Management, 17, 247-271.

Niskala, M., \& Pretes, M. (1995). Environmental reporting in Finland: A note on the use of annual reports. Accounting, Organization and Society, 20(6), 457-66.

O'Sullivan, N., \& O'Dwyer, B. (2009). Stakeholder perspectives on a financial sector legitimation process. Accounting, Auditing \& Accountability, 22(4), 553-587.

Olausson, U. (2011). "We're the ones to blame": Citizens' representations of climate change and the role of the media. Environmental Communication, 5(3), 281-299.

Pollach, I., Scharl, A., \& Weichselbraun, A. (2009). Web content mining for comparing corporate and third-party online reporting: A case study on solid waste management. Business Strategy \& the Environment, 18(3), 137-148.

Ramus, C.A., \& Montiel, I. (2005). When are corporate environmental policies a form of greenwashing? Business \& Society, 44, 377-414.

Scholtens, B. (2009). Corporate social responsibility in the international banking industry. Journal of Business Ethics, 86, 159-175.

Smerecnik, K.R., \& Renegar, V.R. (2010). Capitalistic agency: The rhetoric of BP's Helios Power Campaign. Environmental Communication, 4(2), 152-171.

Spence, C. (2009). Social and environmental reporting and the corporate ego. Business Strategy and the Environment, 18(4), 254-65.

Stray, S., \& Ballantine, J. (2000). A sectoral comparison of corporate environmental reporting and disclosure. Eco-Management and Auditing, 7, 165-77.

Thompson, P., \& Cowton, C.J. (2004). Bringing the environment into bank lending: Implications for environmental reporting. The British Accounting Review, 36, 197-218.

Trumbo, C.W. (1995). Longitudinal modeling of public issues: An application of the agenda-setting process to the issue of global warming. Journalism and Communication Monographs, 152, 1-57.

United Nations (2009). Sustainable development issues. Retrieved December 6, 2011, from http://www.un.org/esa/dsd/susdevtopics/sdt_index.shtml.

US Environmental Protection Agency (2011). From air quality to zero emissions. Retrieved December 6, 2011, from http://www.epa.ie/environmentinfocus/glossary/.

US Environmental Protection Agency (2012). Toxics release inventory. Retrieved September 7, 2012, from http://www.epa.gov/tri/. 
Uscinski, J.E. (2009). When does the public's issue agenda affect the media's issue agenda (and viceversa)? Developing a framework for media-public influence. Social Science Quarterly, 90(4), 798-815.

Zhang, J., \& Swanson D. (2006). Analysis of news media's representation of corporate social responsibility (CSR). Public Relations Quarterly, 51(2), 13-17.

Zucker, H.G. (1978). The variable nature of news media influence. In B.D. Ruben (Ed.), communication yearbook (Vol. 2, pp. 225-240). New Brunswick: Transaction.

Zucker, L.G. (1987). Institutional theories of organizations. Annual Review of Sociology, 13, 443-644. 
Table 1: Number of reports

\begin{tabular}{|c|c|c|c|}
\hline Year & $\begin{array}{c}\text { Financial services } \\
(\mathrm{n}=97)\end{array}$ & $\begin{array}{c}\text { Consumer goods } \\
(\mathrm{n}=110)\end{array}$ & $\begin{array}{c}\text { Sum } \\
(\mathrm{n}=207)\end{array}$ \\
\hline 2008 & 76 & 104 & 190 \\
2007 & 88 & 102 & 190 \\
2006 & 88 & 104 & 192 \\
2005 & 89 & 102 & 191 \\
2004 & 87 & 95 & 182 \\
2003 & 82 & 90 & 172 \\
2002 & 72 & 76 & 148 \\
2001 & 62 & 66 & 128 \\
2000 & 45 & 60 & 105 \\
1999 & 28 & 39 & 76 \\
1998 & 22 & 23 & 61 \\
1997 & 10 & 13 & 33 \\
\hline Sum & & 4 & 1,668 \\
\hline 1996 & 3 & 4 & 4 \\
1995 & 0 & 2 & 2 \\
1994 & 0 & 2 & 4 \\
1993 & 0 & & 2 \\
1992 & 0 & & 4 \\
& & & 2 \\
\hline
\end{tabular}


Table 2: Environmental terms identified for the study

\begin{tabular}{|l|l|}
\hline Terms included in the study: & Terms excluded because of low frequencies: \\
Alternative energy/-ies & (Air quality) \\
Biodegradable & (Carbon neutral) \\
Biodiversity & (Carbon offset) \\
Carbon emissions & (Chlorofluorocarbons) \\
Carbon footprint & (Ecosystem) \\
Climate change & (Natural habitat) \\
CO2 & (Ozone layer) \\
Energy consumption & (Renewable resources) \\
Energy efficiency & (Resource efficiency) \\
Energy use & (Smog) \\
Environmental footprint & (Solar panel/s) \\
Fossil fuel/s & (Waste prevention) \\
Global warming & (Waste production) \\
Greenhouse & (Zero emissions) \\
Groundwater / ground water & \\
Kyoto agreement/protocol & \\
Landfill/s & \\
Pollution & \\
Recycl* & \\
Renewable energy/-ies & \\
Solar energy/power & \\
Sustainability & \\
Sustainable development & \\
Waste management & \\
Wind energy/power & \\
\hline
\end{tabular}


Table 3: Correlations between media coverage and corporate reporting

\begin{tabular}{|c|c|c|c|c|c|}
\hline \multirow[b]{2}{*}{ Term } & \multicolumn{2}{|c|}{$\begin{array}{l}\text { News coverage follows } \\
\text { corporate reports }\end{array}$} & \multirow[b]{2}{*}{ No lag } & \multicolumn{2}{|c|}{$\begin{array}{l}\text { Corporate reports follow } \\
\text { news coverage }\end{array}$} \\
\hline & Lag -2 yrs & Lag $-1 \mathrm{yr}$ & & $\mathrm{Lag}+1 \mathrm{yr}$ & $\mathrm{Lag}+2 \mathrm{yrs}$ \\
\hline Alternative energy & $.8446^{\star *}$ & $.9786^{\star * *}$ & $.8838^{\star * *}$ & $.8861^{* * *}$ & $.7047^{\star}$ \\
\hline Biodegradable & .2431 & .4439 & $.9361^{* * *}$ & .5726 & $.6024^{*}$ \\
\hline Biodiversity & $.8810^{\star * \star}$ & $.8218^{\star *}$ & $.8383^{\star * *}$ & $.8178^{\star *}$ & $.8856^{\star * *}$ \\
\hline Carbon emissions & $.8230^{* *}$ & $.9049^{\star \star \star}$ & $.9761^{* * *}$ & $.9387^{\star * \star}$ & $.9177^{\star * *}$ \\
\hline Carbon footprint & .5846 & $.7726^{\star \star}$ & $.9673^{\star * *}$ & $.9219^{* * *}$ & $.9127^{\star * *}$ \\
\hline Climate change & $.7941^{\star *}$ & $.8612^{\star \star \star x}$ & $.9799^{\star * \star}$ & $.7422^{\star \star}$ & $.8379^{\star \star *}$ \\
\hline $\mathrm{CO} 2$ & $.9193^{\star * *}$ & $.9783^{\star * \star}$ & $.9833^{\star * *}$ & $.9351^{\star * *}$ & $.9548^{\star * *}$ \\
\hline Energy consumption & $.8801^{\star * \star}$ & $.9365^{\star \star \star}$ & $.9378^{\star * *}$ & $.9052^{\star * \star}$ & $.8715^{\star \star \star}$ \\
\hline Energy efficiency & $.9229^{\star * \star}$ & $.9622^{\star \star \star}$ & $.9791^{\star \star \star}$ & $.9052^{\star \star *}$ & $.8917^{\star \star *}$ \\
\hline Energy use & $.9167^{* * *}$ & $.8725^{\star * *}$ & $.8583^{* * *}$ & $.8237^{* * *}$ & $.7907^{\star *}$ \\
\hline Environmental footprint & $.8368^{* \star}$ & $.9255^{* * *}$ & $.9724^{* * *}$ & $.8873^{\star * *}$ & $.8683^{* * *}$ \\
\hline Fossil fuel & $.6879^{\star}$ & $.8034^{\star \star}$ & $.9607^{\star \star \star}$ & $.9227^{\star * *}$ & $.8386^{\star \star \star}$ \\
\hline Global warming & .3842 & $.5951^{\star}$ & $.9195^{\star \star \star}$ & .5426 & .5045 \\
\hline Greenhouse & $.7711^{* *}$ & $.8989^{* * *}$ & $.9643^{\star * *}$ & $.8662^{\star * *}$ & $.8757^{\star * *}$ \\
\hline Groundwater & .1206 & -.4199 & .3463 & .1037 & .2804 \\
\hline Kyoto agreement/protocol & .3385 & .5296 & $.5905^{\star}$ & .5355 & $.6432^{*}$ \\
\hline Landfill/s & .5161 & $.7514^{* *}$ & $.9655^{\star * *}$ & $.8425^{\star * *}$ & $.8198^{* *}$ \\
\hline Pollution & -.2472 & .4079 & $.7828^{\star \star}$ & .4460 & .5550 \\
\hline $\operatorname{Recycl}^{\star}$ & $.7234^{*}$ & $.8941^{\star * *}$ & $.9875^{\star * *}$ & $.9061^{\star * *}$ & $.8820^{\star * *}$ \\
\hline Renewable energy & $.8596^{\star * *}$ & $.9431^{\star \star *}$ & $.9284^{* * *}$ & $.8701^{\star * *}$ & $.8456^{\star * *}$ \\
\hline Solar energy & $.8640^{* * *}$ & $.8450^{\star * *}$ & $.7203^{\star *}$ & $.6055^{*}$ & .5562 \\
\hline Sustainability & $.9372^{\star \star \star}$ & $.9803^{\star * *}$ & $.9894^{\star \star \star}$ & $.9534^{\star * *}$ & $.9526^{\star * *}$ \\
\hline Sustainable development & $.6307^{\star}$ & $.7668^{\star \star}$ & $.8328^{\star * *}$ & $.7701^{\star \star}$ & $.7848^{\star \star}$ \\
\hline Waste management/handling & .0772 & .4026 & $.8773^{\star * *}$ & .3440 & .4272 \\
\hline Wind energy & $.8130^{\star *}$ & $.8490^{\star \star \star}$ & $.8560^{\star \star \star}$ & $.8131^{\star *}$ & $.8328^{\star \star \star}$ \\
\hline
\end{tabular}

N.B.: A lag of +2 , for example, means that the correlation between news coverage from 2000 and corporate reports from 2002 is calculated. 
Figure 1: Frequency comparison of alternative energy/ies and carbon emissions

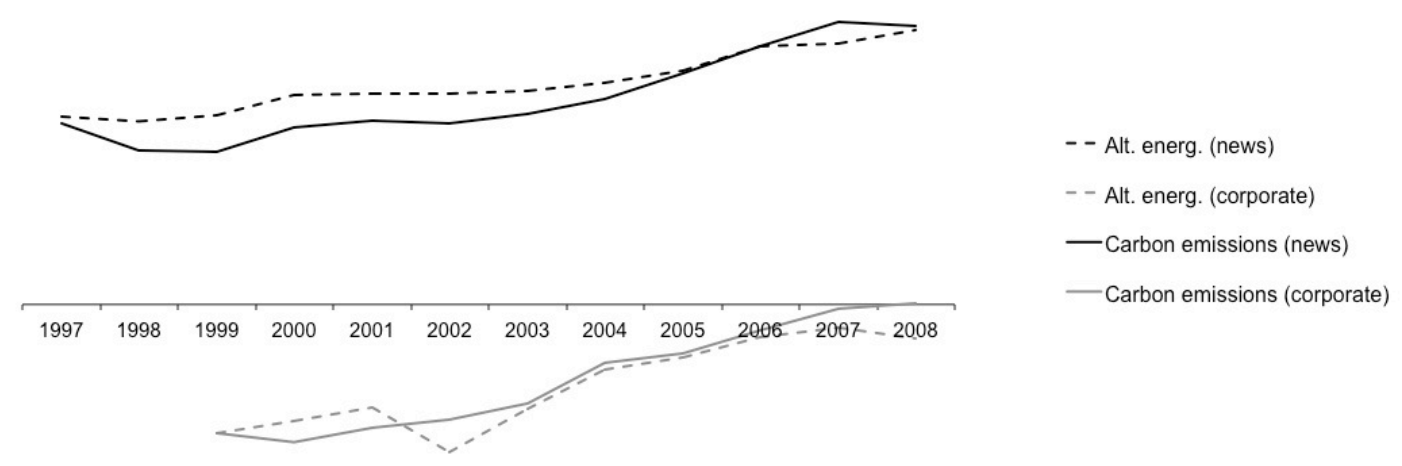

Figure 2: Frequency comparison of carbon footprint and environmental footprint

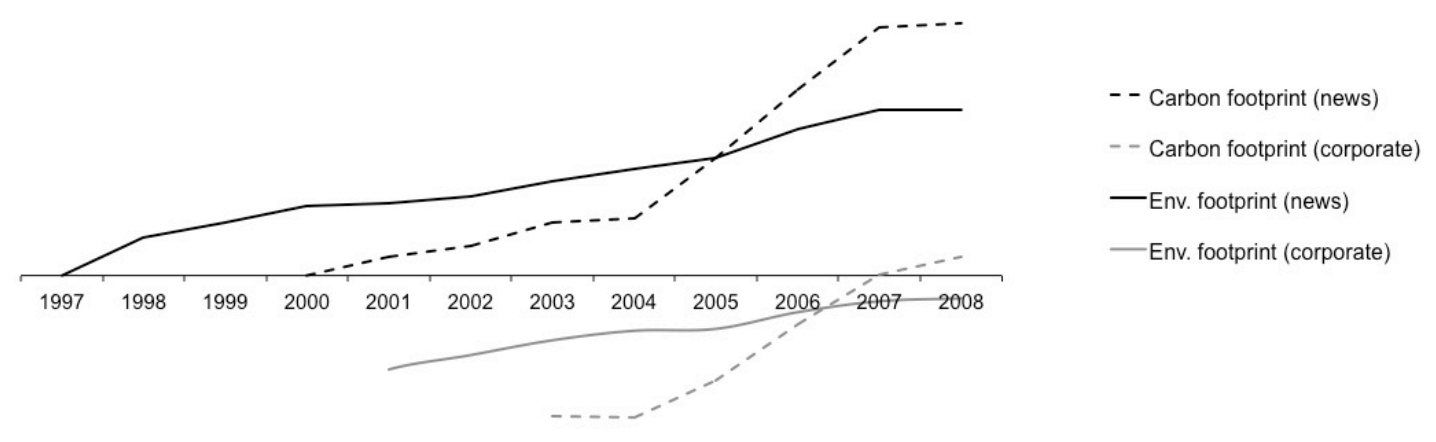


Figure 3: Comparison between financial-services companies and consumer-goods companies

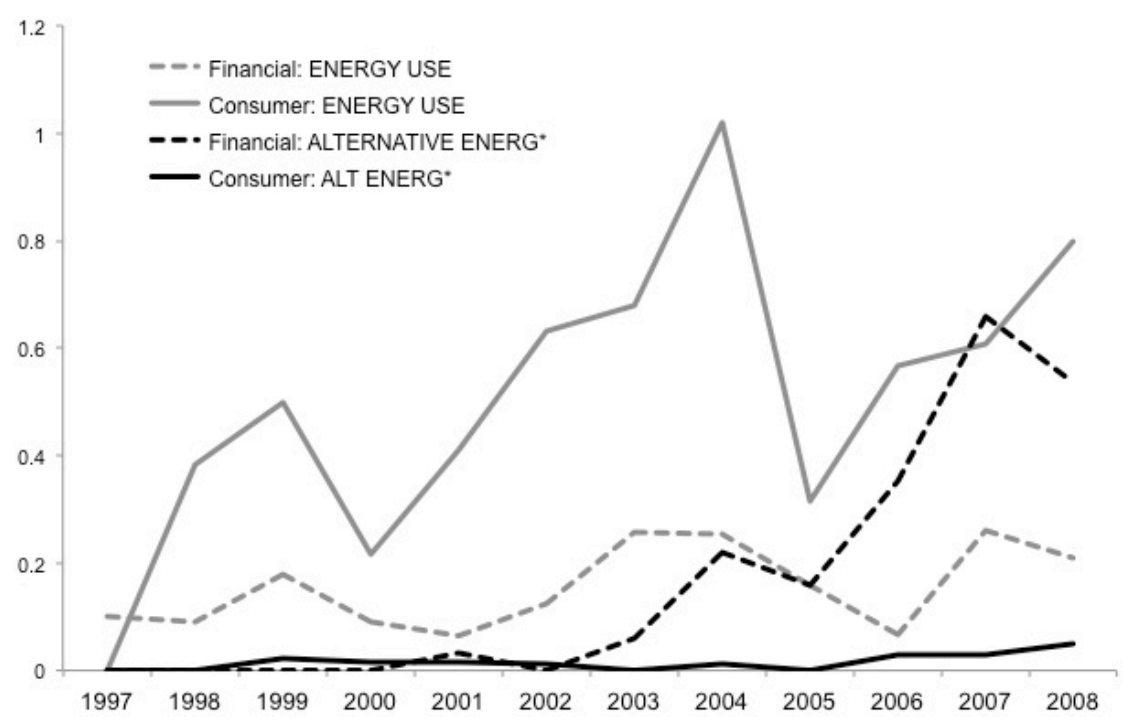

Figure 4: Comparison between financial-services companies and consumer-goods companies

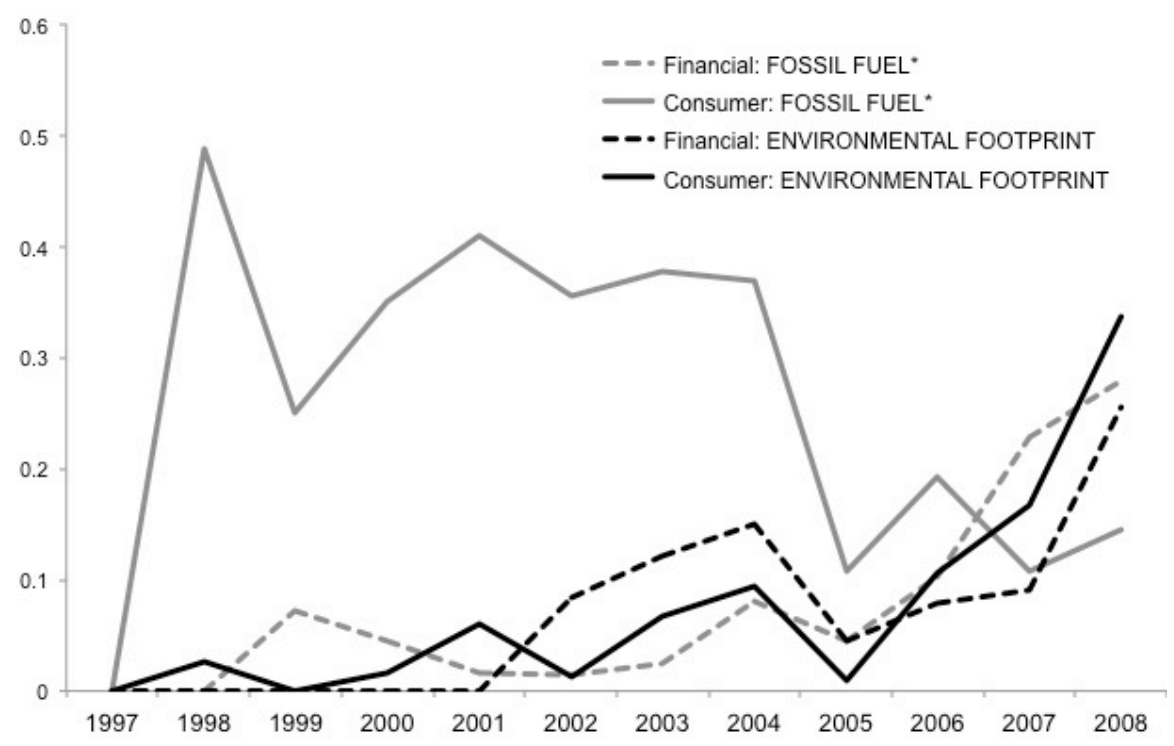

